\title{
Identifikasi Kerusakan Shaft Roda Gigi Pompa Oli Diesel Engine Dengan Menggunakan Metode Fault Tree Analysis
}

\author{
Wilarso $^{1 *}$, Wisnu Pracoyo ${ }^{2 * *}$ \\ ${ }^{1,2}$ Program Studi Teknik Mesin, Sekolah Tinggi Teknologi Muhammadiyah Cileungsi \\ J1. Anggrek No. 25 Cileungsi, Bogor 16820, Indonesia, Telp: 021-82495502 \\ *wilarso@sttmcileungsi.ac.id,**wisnupracoyo@gmail.com
}

\begin{abstract}
A damage to the oil pump drive shaft on one of the generator sets PT.X. Failure begins with an indication of a decrease in oil pressure where the oil pressure indicator points to the number 0 (zero). Based on the electronic control module (ECM) download data, it was noted that the unit had experienced 4 times low oil pressure warning and 4 times low oil pressure shutdown. During visual checking, the crankshaft suddenly stops spinning (jammed). To identify the initial damage associated with low oil pressure and the crankshaft stops rotating (crankshaft jammed), an oil pump component is dismantled. In a visual inspection found broken oil pump drive gear. In identifying oil pump failure and analysis using the Fault Tree Analysis method. Based on the FTA the oil pump failure is caused by 4 (four) factors including, 1. Oil quality, 2. Contamination control, 3, Material quality, and 4. Maintenance, from the four causes which are the main causes of control contamination, due to the presence of material metal above the axle goes to the oil pump. Based on the initial material test the broken gear begins with the outer circle and the final fracture in the center of the gear shaft, from the microstructure testing of the fracture shape there is no beachmark on the broken surface and the final shape of the rough fracture, that the gear shaft is broken in a short time.
\end{abstract}

Keywords: Gear Shaft, Crankshaft Jammed, Fault Tree Analysis.

\section{PENDAHULUAN}

Pompa oli untuk menghisap oli dari bak penampungan dan mengalirkan menuju sistem pelumasan diesel engine. Oli pelumas dibutuhkan diesel engine untuk melumasi komponen yang berputar agar tidak terjadi kontak antara dua benda yang bergerak dan tidak menimbulkan gesekan serta membentuk lapisan oil film diantara benda yang berputar. Sebelum oli menuju ke sistem pelumasan harus dilakukan penyaringan partikel melalui Screen As untuk penyaring partikel yang besar sebelum menuju ke pompa oli, selanjutnya oli mengalir menuju ke filter oli untuk menyaring partikel lebih kecil (micron) dan kemudian mengalir menuju ke komponen-komponen diesel engine yang membutuhkan pelumasan, adapun komponen yang harus mendapatkan pelumasan diantaranya: turbocharger, camshaft, rocker arm, valve, bearing, connecting rod, crankshaft, gear, dll.

Kegagalan diawali dengan adanya indikasi penurunan tekanan oli, dimana indikator tekanan oli menunjukkan angka 0 (nol), terdapat indikasi 4 kali low oil pressure warning \& 4 kali low oil pressure warning shutdown, disebabkan karena adanya penurunan tekanan oli (low oil pressure) dibawah batas minimum spesifikasi $373 \mathrm{kPa}$. Untuk mengidentifikasi awal kerusakan tersebut terkait dengan low oil pressure dan poros engkol berhenti berputar (crankshaft jammed), dilakukan pembongkaran terhadap komponen pompa oli. 


\section{Published September 2019 \\ Jurnal Rekayasa Material, Manufaktur dan Energi http://jurnal.umsu.ac.id/index.php/RMME}

Pada gambar 1 dijelaskan sebelum dilakukan pekerjaan overhaul (STOH) tekanan oli cenderung stabil, diantara 395-410 kPa, dengan beban 1050-1100 kW. Setelah dilakukan STOH tekanan oli tercatat mengalami penurunan hingga tekanan dibawah normal (370 $\mathrm{kPa})$ selama 10 jam beroperasi.

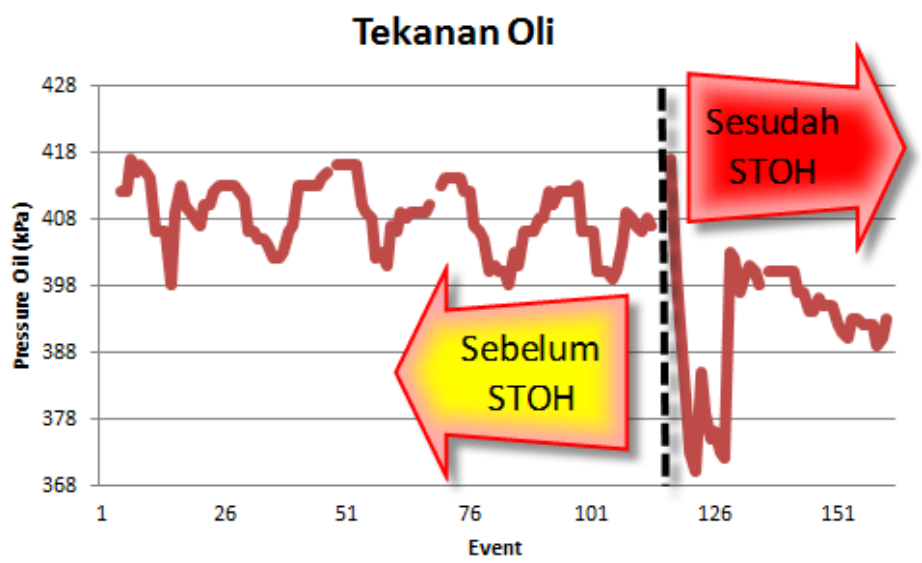

Gambar 1. Trending Tekanan oli

Kinerja diesel engine terdapat 4 (empat) sistem diantaranya: sistem pelumasan, sistem pendingin, sistem bahan bakar, sistem air intake dan exhaust, dari ke empat sistem tersebut mempunyai dampak yang signifikan seperti sistem pelumasan. Pompa oli ditempatkan pada sisi kanan engine, penggerak pompa oli terkoneksi dengan pompa air. Pada gambar 2 menunjukkan bagian-bagian komponen pompa pada saat pemasangan.

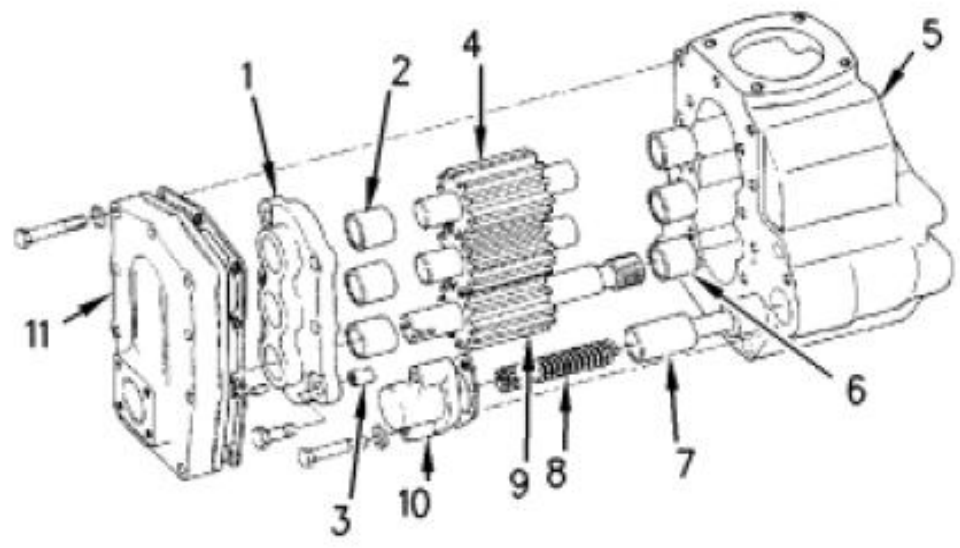

Gambar 2. Bagian-Bagian oil pump

Dalam melakukan analisa kerusakan shaft roda gigi pompa oli , berdasarkan dari beberapa-berapa referensi analisa sebelumnya, diantaranya:

- Fault tree analysis (FTA) adalah metode yang banyak digunakan untuk menganalisis logika kegagalan sistem dan menghitung keandalan keseluruhan. Namun, penerapan FTA konvensional memiliki beberapa kekurangan, mis. dalam menangani ketidakpastian, memungkinkan penggunaan variabel linguistik, dan mengintegrasikan kesalahan manusia dalam model logika kegagalan [1]. 


\section{Published September 2019 \\ Jurnal Rekayasa Material, Manufaktur dan Energi http://jurnal.umsu.ac.id/index.php/RMME}

- $\quad$ FTA merupakan perangkat untuk mengidentifikasi penyebab kegagalan sistem. FTA bekerja dengan menentukan kegagalan yang disebut sebagai "top event", selanjutnya top event diidentifikasi hubungan faktor penyebab berbagai peristiwa kegagalan dengan pohon kesalahan yang menggunakan gerbang logika sederhana "and" dan "or". [2]

- $\quad$ FTA (Fault Tree Analysis) dilakukan untuk menemukan akar penyebab dari setiap peristiwa yang tidak diinginkan. Akar penyebab yang telah diidentifikasi akan dikategorikan sebagai risiko internal yang dapat terjadi dalam proses produksi [3]

\section{METODE PENELITIAN}

\section{Sistem Pelumasan}

Aliran sistem pelumasan yang ada didalam engine sesuai dengan diagram, dimana posisi kerusakan pada pompa oli.

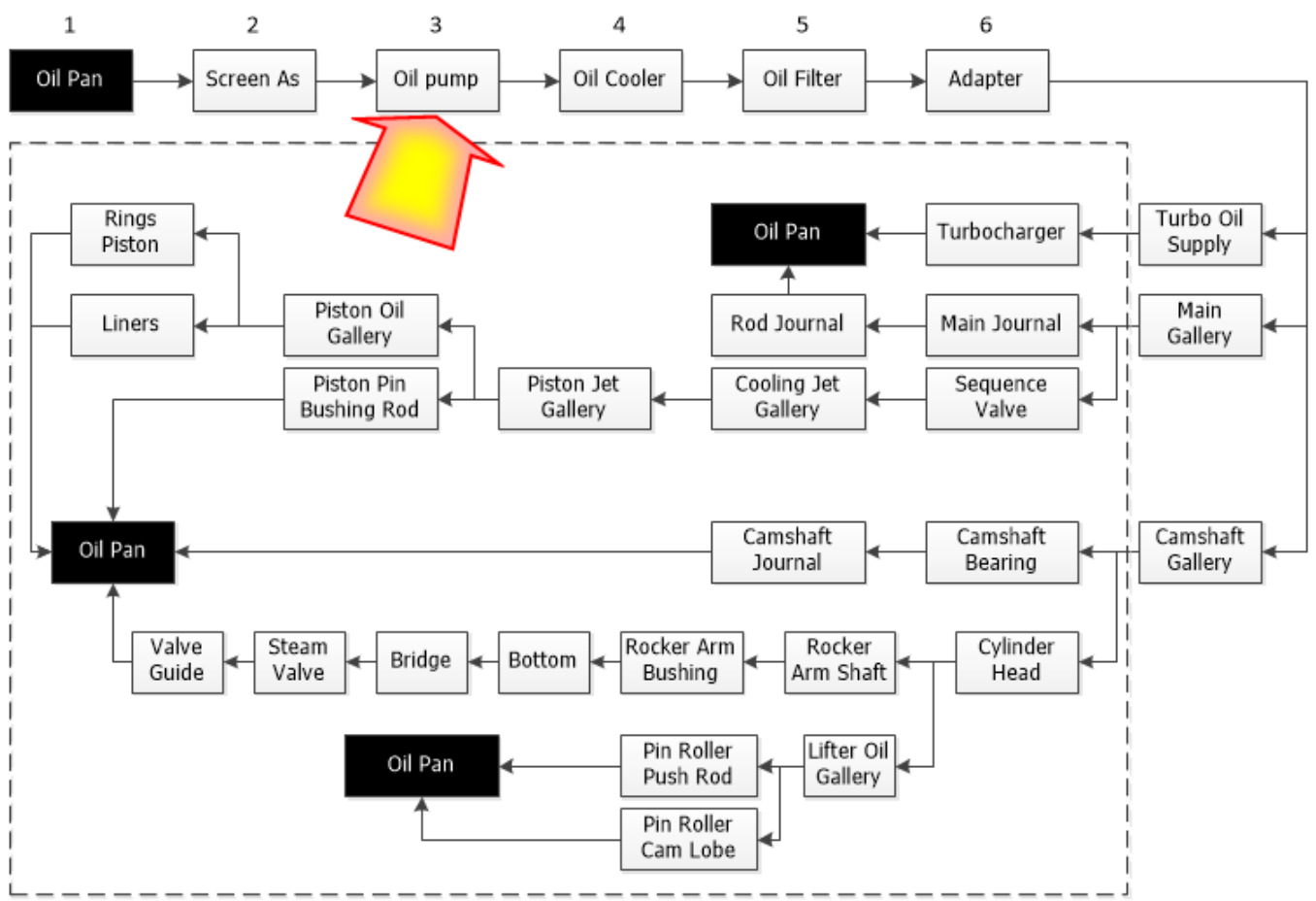

Gambar 3. Alir oli pelumas

\section{Visual inspeksi oil filter.}

Setelah dilakukan pengecekan ada oil filter, di bagian luar element oli filter ditemukan partikel logam yang bersifat magnetos. 


\section{Published September 2019 \\ Jurnal Rekayasa Material, Manufaktur dan Energi http://jurnal.umsu.ac.id/index.php/RMME}

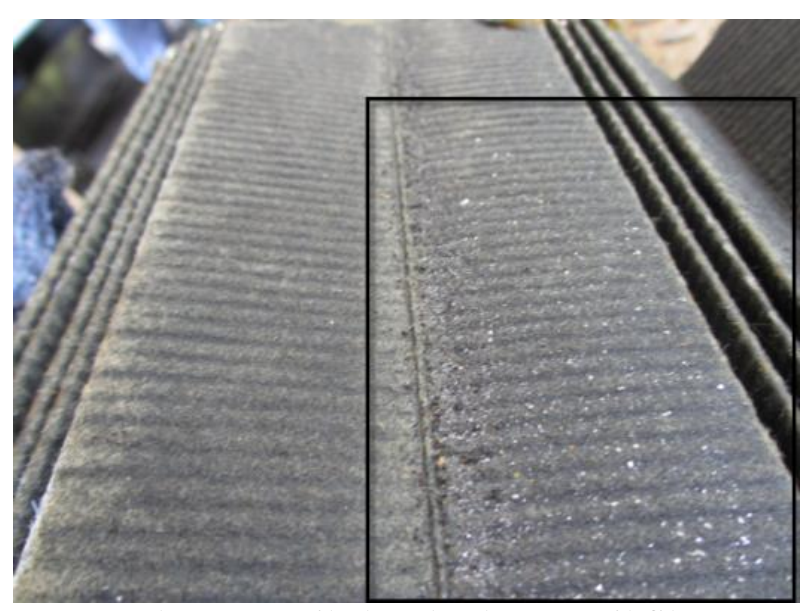

Gambar 4. Partikel pada element oil filter.

\section{Pengecekan screen as.}

Dibagian dalam screen as tidak ditemukan partikel logam yang besar berada di bagian dalam screen as. Kontaminasi pada saluran oli yang ada di engine, harus benar-benar diperhatikan saat melakukan pekerjaan maupun setelah melakukan pekerjaan. Dimana kontaminasi yang berada di saluran oli tersebut akan mengakibatkan kerusakan fatal.

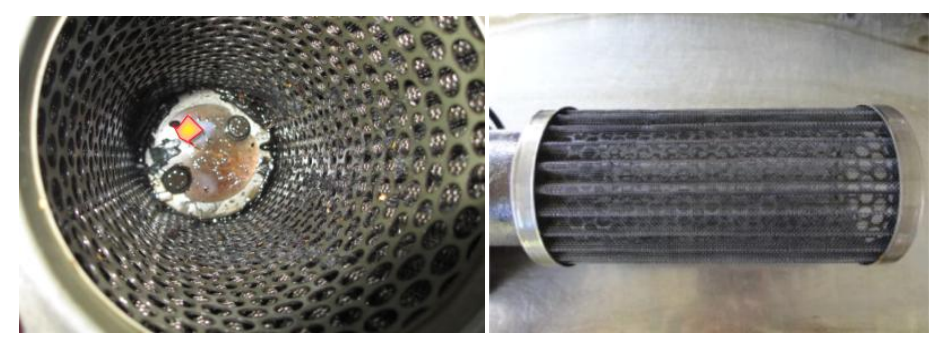

Gambar 5. Partikel di screen as

\section{Fault Tree Analysis.}

Fault Tree Analysis adalah alat penilaian risiko yang sangat efektif tetapi ketika datang ke sistem yang cukup kompleks, yang mencakup sejumlah besar peralatan dan variabel proses, pohon kesalahan menjadi sangat besar dan membutuhkan waktu yang cukup lama untuk diselesaikan [4]. Dalam bidang analisis keselamatan dan keandalan, pemodelan yang tepat untuk sistem teknis yang kompleks selama pengembangan dan untuk tujuan evaluasi sangat penting. Secara tradisional, model pohon kesalahan telah digunakan untuk mencapai ini, dan, baru-baru ini, model Petri-net stokastik telah mulai digunakan [5].

Gerbang logika sederhana ini dapat menggambarkan bentuk kegagalan dan apa pemicu terjadinya kegagalan, baik itu disebabkan oleh kegagalan tunggal ataupun beberapa kegagalan yang terjadi dalam waktu yang sama [2]. Di sisi lain, keuntungan terbesar menggunakan FTA adalah bahwa dimulai dari acara teratas yang dipilih oleh pengguna untuk minat tertentu dan pohon yang dikembangkan akan mengidentifikasi akar permasalahan. FTA memiliki kemampuan untuk digunakan dengan komputer dan menghasilkan hasil menggunakan aplikasi komputer untuk analisis yang lebih baik. 


\section{Published September 2019 \\ Jurnal Rekayasa Material, Manufaktur dan Energi http://jurnal.umsu.ac.id/index.php/RMME}

Tabel 1. Simbol Fault Tree Analysis

\begin{tabular}{|c|c|c|}
\hline Simbol & Keterangan & Definisi \\
\hline & AND Gate & $\begin{array}{l}\text { Kejadian kegagalan sistem terjadi } \\
\text { apabila satu atau komponen lainnya } \\
\text { mengalami kegagalan }\end{array}$ \\
\hline & OR Gate & $\begin{array}{l}\text { Kejadian kegagalan sistem terjadi } \\
\text { apabila satu atau komponen lainnya } \\
\text { mengalami kegagalan }\end{array}$ \\
\hline & Inhibit Event & $\begin{array}{l}\text { output hanya akan terjadi jika input } \\
\text { menghambat kejadian }\end{array}$ \\
\hline & Basic Event & Penyebab mula kegagalan sistem \\
\hline & $\begin{array}{l}\text { Intermediate } \\
\text { Event: }\end{array}$ & $\begin{array}{l}\text { Hasil dari interaksi yang berbeda dalam } \\
\text { kejadian }\end{array}$ \\
\hline & $\begin{array}{l}\text { Undeveloped } \\
\text { Event: }\end{array}$ & $\begin{array}{l}\text { Ketika informasi yang diperlukan tidak } \\
\text { tersedia, kejadian tidak dapat } \\
\text { dikembangkan lebih lanjut. }\end{array}$ \\
\hline & $\begin{array}{l}\text { Transfer } \\
\text { Symbols: }\end{array}$ & $\begin{array}{l}\text { Digunakan untuk mentransfer pohon } \\
\text { kesalahan ke lokasi lain di lembar yang } \\
\text { berbeda }\end{array}$ \\
\hline
\end{tabular}

\section{Visual inspeksi pada roda gigi pompa oli.}

Gambar 2 dijelaskan dari ketiga roda gigi (1. Drive, 2. Idler, 3. Driven), posisi patahnya di roda gigi drive di posisi ujung yang menuju dudukan pompa air yang ada di engine.

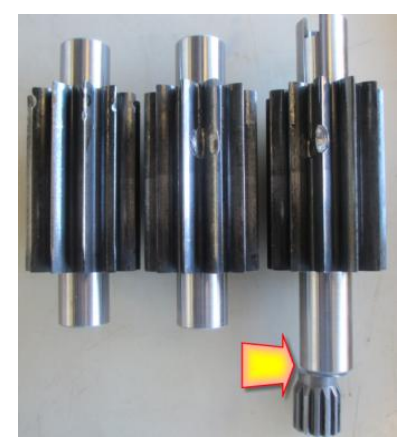

Gambar 6. Roda gigi pompa oli patah

\section{Patahan Shaft Roda Gigi.}

Di sisi bagian luar shaft roda gigi, terindikasi berwarna hitam di beberapa bagian, dimana dari bentuk kerusakan tersebut brittle (tiba-tiba). 


\section{Published September 2019 \\ Jurnal Rekayasa Material, Manufaktur dan Energi http://jurnal.umsu.ac.id/index.php/RMME}

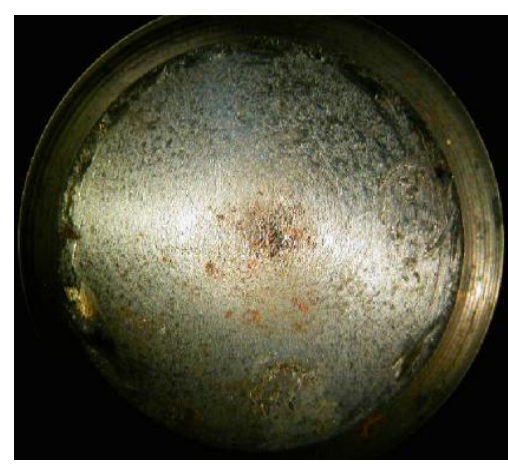

Gambar 7. Photo makrografi patahan roda gigi

\section{Final Fracture.}

Final fracture pada shaft roda gigi yang patah, dan final fracture di posisi tengah shaft roda gigi.

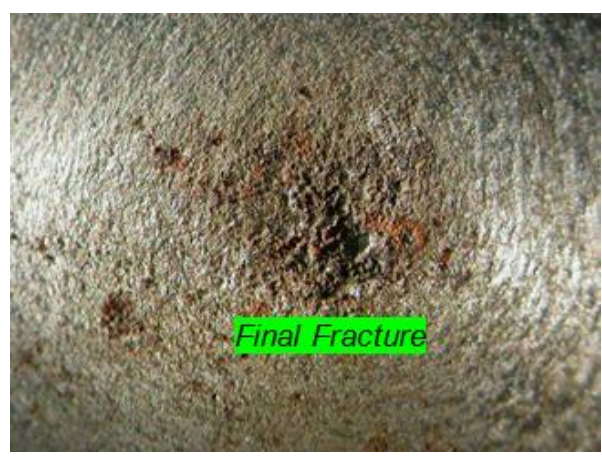

Gambar 8. Final Fracture

Figure Struktur Mikro.

Bentuk patahan di bagian final fracture, dengan permukaan kasar yang mengindikasikan bahwa kerusakan tersebut cukup singkat kejadiannya, sesuai dengan gambar 9.
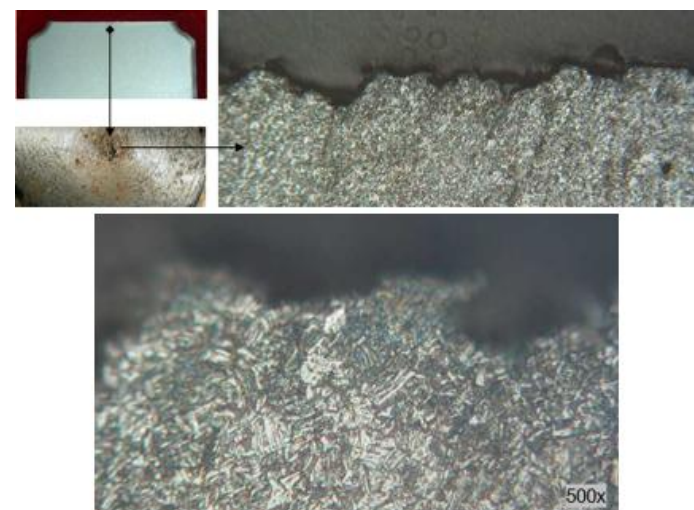

Gambar 9. Struktur mikro daerah cacat dan daerah patah akhir (final fracture)

\section{Pengujian Komposisi Kimia.}

Dari hasil pengujian komposisi kimia wear element $\mathrm{C}, \mathrm{Si}, \mathrm{Mn}, \mathrm{Cr}, \mathrm{Ni}, \mathrm{Mo}, \mathrm{Cu}, \mathrm{S}$ dan $\mathrm{P}$, dalam katerogy normal sesuai dengan JIS 4103 SNCM 220. 


\section{Published September 2019 \\ Jurnal Rekayasa Material, Manufaktur dan Energi http://jurnal.umsu.ac.id/index.php/RMME}

Tabel 2: Hasil pengujian shaft roda gigi pompa oli

\begin{tabular}{|c|c|c|}
\hline \multicolumn{2}{|c|}{ Hasil Pengujian } & JIS 4103 SNCM 220 \\
\hline Element & $(\%)$ & $(\%)$ \\
\hline $\mathrm{Fe}$ & 97.29 & - \\
\hline $\mathrm{C}$ & 0.21 & $0.17-0.23$ \\
\hline $\mathrm{Si}$ & 0.22 & $015-0.35$ \\
\hline $\mathrm{Mn}$ & 0.83 & $0.63-0.90$ \\
\hline $\mathrm{Cr}$ & 0.52 & $0.40-0.65$ \\
\hline $\mathrm{Ni}$ & 0.45 & $0.40-0.70$ \\
\hline $\mathrm{Mo}$ & 0.19 & $0.15-0.30$ \\
\hline $\mathrm{Cu}$ & 0.21 & $0.30 \mathrm{Max}$ \\
\hline $\mathrm{A} 1$ & 0.029 & - \\
\hline $\mathrm{V}$ & 0.026 & - \\
\hline $\mathrm{Nb}$ & 0.028 & - \\
\hline $\mathrm{Ti}$ & 0.22 & - \\
\hline $\mathrm{S}$ & 0.021 & $0.030 \mathrm{Max}$ \\
\hline $\mathrm{P}$ & 0.0086 & $0.030 \mathrm{Max}$ \\
\hline
\end{tabular}

\section{HASIL DAN PEMBAHASAN}

Hasil pengamatan dan pemeriksaan terhadap permukaan shaft roda gigi pompa oli: Transmisi roda gigi patah pada daerah berdiameter kecil di radius, momen yang bekerja cukup besar, patahan membentuk sudut tegak lurus terhadap bidang patah dan permukaan rata. Tidak ditemukan adanya patah lelah (fatigue fracture), jika ada indikasi patah lelah terdapat beachmark. Terdapat cacat-cacat pada daerah tepi patahan, akibat gesekan saat patah dan final fracture terletak ditengah. Dari bentuk patahan serta indikasi penurunan tekanan oli, kerusakan shaft roda gigi pompa oli disebabkan oleh adanya partikel logam besar di saluran oli pelumas menuju pompa oli, sehingga menghambat perggerakan pompa oli dan menyebabkan pompa oli berhenti berputar. Karena beban torsi yang besar dan melebihi kemampuan shaft pompa oli dan pompa oli berhenti mendadak dan akhirnya patah.

\section{KESIMPULAN}

Patahnya shaft roda gigi pompa oli ini disebabkan oleh material logam yang menghambat perggerakan roda gigi, pada saat material logam berada di atas screen as dan dengan dioperasikan diesel engine material logam bergerak menuju pompa oli yang mengakibatkan gesekan antara material logam dengan roda gigi.

\section{UCAPAN TERIMA KASIH}

Terima kasih kami ucapkan rekan-rekan teknisi dan akademisi yang telah memberikan kesempatan dalam melakukan penelitian material pompa oli tersebut.

\section{REFERENSI}

[1] Y. A. Mahmood, A. Ahmadi, A. K. Verma, A. Srividya, and U. Kumar, "Fuzzy fault tree analysis: A review of concept and application," Int. J. Syst. Assur. Eng. Manag., vol. 4, no. 


\section{Published September 2019 \\ Jurnal Rekayasa Material, Manufaktur dan Energi http://jurnal.umsu.ac.id/index.php/RMME}

\section{1, pp. 19-32, 2013.}

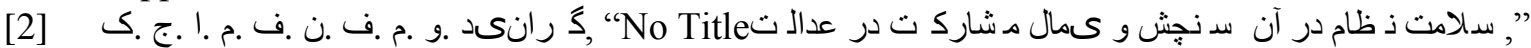
vol. VII, no. 2, pp. 77-87, 1390.

[3] N. A. Wessiani and F. Yoshio, "Failure mode effect analysis and fault tree analysis as a combined methodology in risk management," IOP Conf. Ser. Mater. Sci. Eng., vol. 337, no. $1,2018$.

[4] A. A. Baig, R. Ruzli, and A. B. Buang, "Reliability Analysis Using Fault Tree Analysis: A Review," Int. J. Chem. Eng. Appl., vol. 4, no. 3, pp. 169-173, 2013.

[5] K. Buchacker, "Modeling with extended fault trees," Proc. IEEE Int. Symp. High Assur. Syst. Eng., vol. 2000-Janua, pp. 238-246, 2000. 